NASA/TM-2002-211913



\title{
Development of a High Performance Acousto-Ultrasonic Scan System
}

\section{D.J. Roth}

Glenn Research Center, Cleveland, Ohio

R.E. Martin and L.M. Harmon

Cleveland State University, Cleveland, Ohio

A.L. Gyekenyesi

Ohio Aerospace Institute, Brook Park, Ohio

H.E. Kautz

Cleveland State University, Cleveland, Ohio 
Since its founding, NASA has been dedicated to the advancement of aeronautics and space science. The NASA Scientific and Technical Information (STI) Program Office plays a key part in helping NASA maintain this important role.

The NASA STI Program Office is operated by Langley Research Center, the Lead Center for NASA's scientific and technical information. The NASA STI Program Office provides access to the NASA STI Database, the largest collection of aeronautical and space science STI in the world. The Program Office is also NASA's institutional mechanism for disseminating the results of its research and development activities. These results are published by NASA in the NASA STI Report Series, which includes the following report types:

- $\quad$ TECHNICAL PUBLICATION. Reports of completed research or a major significant phase of research that present the results of NASA programs and include extensive data or theoretical analysis. Includes compilations of significant scientific and technical data and information deemed to be of continuing reference value. NASA's counterpart of peerreviewed formal professional papers but has less stringent limitations on manuscript length and extent of graphic presentations.

- TECHNICAL MEMORANDUM. Scientific and technical findings that are preliminary or of specialized interest, e.g., quick release reports, working papers, and bibliographies that contain minimal annotation. Does not contain extensive analysis.

- CONTRACTOR REPORT. Scientific and technical findings by NASA-sponsored contractors and grantees.
- CONFERENCE PUBLICATION. Collected papers from scientific and technical conferences, symposia, seminars, or other meetings sponsored or cosponsored by NASA.

- SPECIAL PUBLICATION. Scientific, technical, or historical information from NASA programs, projects, and missions, often concerned with subjects having substantial public interest.

- TECHNICAL TRANSLATION. Englishlanguage translations of foreign scientific and technical material pertinent to NASA's mission.

Specialized services that complement the STI Program Office's diverse offerings include creating custom thesauri, building customized databases, organizing and publishing research results ... even providing videos.

For more information about the NASA STI Program Office, see the following:

- Access the NASA STI Program Home Page at http://www.sti.nasa.gov

- E-mail your question via the Internet to help@sti.nasa.gov

- Fax your question to the NASA Access Help Desk at 301-621-0134

- Telephone the NASA Access Help Desk at 301-621-0390

- Write to:

NASA Access Help Desk

NASA Center for AeroSpace Information 7121 Standard Drive

Hanover, MD 21076 
NASA/TM-2002-211913

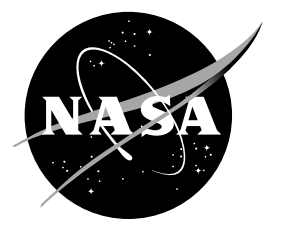

\section{Development of a High Performance Acousto-Ultrasonic Scan System}

D.J. Roth

Glenn Research Center, Cleveland, Ohio

R.E. Martin and L.M. Harmon

Cleveland State University, Cleveland, Ohio

A.L. Gyekenyesi

Ohio Aerospace Institute, Brook Park, Ohio

H.E. Kautz

Cleveland State University, Cleveland, Ohio

Prepared for the

29th Annual Review of Progress in Quantitative Nondestructive Evaluation (QNDE) sponsored by the Quantitative Nondestructive Evaluation Programs

Bellingham, Washington, July 14-19, 2002

National Aeronautics and

Space Administration

Glenn Research Center 
Trade names or manufacturers' names are used in this report for identification only. This usage does not constitute an official endorsement, either expressed or implied, by the National Aeronautics and Space Administration.

Available from

NASA Center for Aerospace Information 7121 Standard Drive

Hanover, MD 21076
National Technical Information Service 5285 Port Royal Road Springfield, VA 22100

Available electronically at http:/ /gltrs.grc.nasa.gov 


\title{
DEVELOPMENT OF A HIGH PERFORMANCE ACOUSTO-ULTRASONIC SCAN SYSTEM
}

\author{
D.J. Roth \\ National Aeronautics and Space Administration \\ Glenn Research Center \\ Cleveland, Ohio 44135 \\ R.E. Martin and L.M. Harmon \\ Cleveland State University \\ Cleveland, Ohio 44120 \\ A.L. Gyekenyesi \\ Ohio Aerospace Institute \\ Brook Park, Ohio 44142 \\ H.E. Kautz \\ Cleveland State University \\ Cleveland, Ohio 44120
}

\begin{abstract}
Acousto-ultrasonic (AU) interrogation is a single-sided nondestructive evaluation technique employing separated sending and receiving transducers. It is used for assessing the microstructural condition/distributed damage state of the material between the transducers. AU is complementary to more traditional NDE methods such as ultrasonic c-scan, $\mathrm{x}$-ray radiography, and thermographic inspection that tend to be used primarily for discrete flaw detection. Through its history, AU has been used to inspect polymer matrix composite, metal matrix composite, ceramic matrix composite, and even monolithic metallic materials. The development of a high-performance automated AU scan system for characterizing within-sample microstructural and property homogeneity is currently in a prototype stage at NASA. In this paper, a review of essential AU technology is given. Additionally, the basic hardware and software configuration, and preliminary results with the system, are described.
\end{abstract}

\section{BACKGROUND}

\section{What is Acousto-Ultrasonics?}

Acousto-ultrasonic (AU) interrogation is a single-sided nondestructive evaluation technique employing separated sending and receiving transducers. It is used for assessing the microstructural condition/distributed damage state of the material between the transducers. (figure 1).

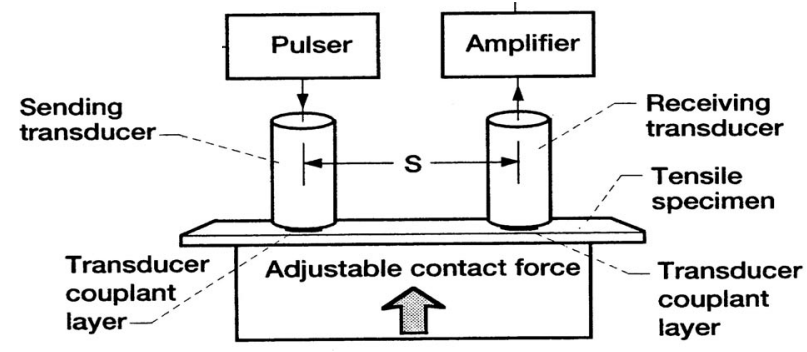

FIGURE 1. Schematic of Acousto-ultrasonic experimental setup. $\mathrm{S}=$ distance between sending and receiving transducers. 
AU as a field of ultrasonic plate wave empirical study originated in the 1970s at NASA Glenn Research Center [1-3] and is most commonly applied with transducers placed in contact with the sample under test. However, the use of lasers for ultrasonic generation, and laser interferometry detection or air-coupled ultrasonic transducers for receiving the lamb waves (in this case leaky) has also been successfully employed [4,5]. The key factor in $\mathrm{AU}$ is that the relationship between the ultrasonic wavelength $(\lambda)$ and material thickness (h) likely results in a diffuse field of multiple plate wave modes. The regime where higherorder plate wave modes are generated is:

$$
\lambda / \mathrm{h}<2
$$

and $\lambda$ can be approximately determined from:

$$
\lambda=\mathrm{V} / \mathrm{f}
$$

where $\mathrm{f}=$ center frequency of employed sending transducer and $\mathrm{V}=$ the longitudinal velocity in the propagation direction and is usually estimated from pulse-echo velocity measurements, resonance velocity measurements, or published values. AU analysis is based upon the premise of internal absorption and scattering mechanisms being primarily responsible for ultrasonic attenuation with minimal damping due to air, fixturing, and specimen edges. Under these conditions, the morphology of the waveform at the receiving transducer is that of a short duration rise (dominated by early plate wave modes $\mathrm{L}_{11}$ [first symmetric \{longitudinal\} mode] and $\mathrm{L}_{12}$ [first anti-symmetric \{shear mode]) followed by an exponentially-decaying portion. A "model" waveform is shown in figure 2. Described in terms of energy density $\left(|\varphi(f, t)|^{2}\right.$ ) (rather than amplitude $\varphi(f, t)$ ), the exponential decaying portion of the waveform can be described by [2]:

$$
|\varphi(f, t)|^{2}=K(f) * \operatorname{Exp}(-\beta(f) t)
$$

where $\beta(f)$ is the frequency-dependent ultrasonic decay rate which describes wave decay over time, and $K(f)$ is the initial energy. $\beta(f)$ is analogous to the frequency-dependent attenuation coefficient $\alpha(f)$ which describes wave decay over distance. Since there is no precise wave path length that is easily defined, the current methods for calculation of $\beta$ (f) requires first dividing the time domain wave into time partitions, obtaining power spectral density (PSD) of each partitioned portion of the time domain waveform, calculating the area under each PSD curve to obtain energy density (zeroth moment) [6], plotting the energy density values versus the midpoint of each time partition, and obtaining the best exponential fit of this curve to obtain $K(f)$ and $\beta(f)$. Calculation methods for $\beta(f)$ are described in more detail by Kautz [7]. Several other time- and frequency-domain parameters are calculated from the AU signal and have proven useful in assessing structural state changes in test samples. These include the zeroth moment and centroid (center frequency) of the overall PSD, and centroid mean time which essentially provides a measure of time duration of the waveform [7]. The latter two properties and $\beta(f)$ are ratioand rate-based properties, respectively, with such normalization helping to minimize the effects of boundary condition changes during investigations using AU. Many other parameters of the time- and frequency-domain waveforms are being investigated in terms of their effectiveness for differentiation of material state. 


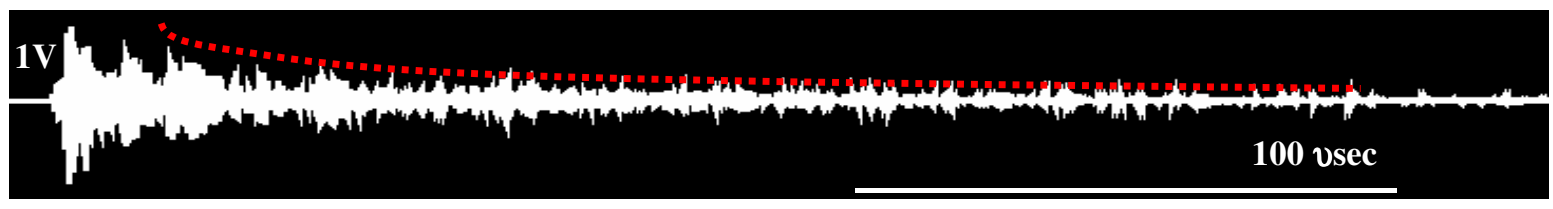

FIGURE 2. Typical morphology of waveform at receiving transducer with dashed line illustrating exponential decay. Voltage (Y-axis) versus time (X-axis).

\section{Why Acousto-Ultrasonics for NDE Inspection?}

Mechanical and environmental loads applied to composite materials can cause distributed damage (as well as discrete defects) that plays a significant role in degradation of physical properties. Such damage includes fiber/matrix debonding (interface failure), matrix microcracking, and fiber fracture and buckling. Investigations at NASA Glenn Research Center have shown that traditional NDE scan inspection methods such as ultrasonic c-scan, x-ray imaging, and thermographic imaging tend to be more suited to discrete defect detection rather than the characterization of accumulated distributed microdamage in composites. Since AU is focused on assessing the distributed microdamage state of the material in between the sending and receiving transducers, it has proven quite suitable for the assessment of relative composite material state. Indeed, throughout its history, AU has been successfully used to inspect polymer matrix composite, metal matrix composite, ceramic matrix composite materials, and even metallic monolithic materials [1-3,8-12]. One major success story at NASA Glenn Research Center with AU measurements has been the correlation between $\beta(f)$ and mechanical modulus (stiffness) in Silicon Carbide/Silicon Carbide ( $\mathrm{SiC} / \mathrm{SiC}$ ) ceramic matrix composite samples seen during fatigue experiments (figure 3). As shown in figure 3, $\beta(\mathrm{f})$ increased as modulus decreased for the ceramic matrix composite tensile fatigue samples. The likely microstructural reason for the decrease in modulus (and increase in $\beta(f)$ ) is matrix microcracking commonly occurring during fatigue testing of these materials [13]. $\beta(\mathrm{f})$ has shown capability to track the pattern of transverse cracking and fiber breakage in these composites [14].

In summarizing $\mathrm{AU}$ advantages:

- AU measurements can be performed directionally allowing correlations to be made between AU parameters and directionally-dependent material properties.

- AU measurements appear to be particularly sensitive to stiffness/modulus changes and changes in microstructure such as distributed microcrack formation and porosity variation.

- AU has been successfully implemented with contact transducers for sending and receiving, as well as laser generation in combination with air-coupling ultrasonic reception. Laser detection of lamb waves also has been shown [5].

- $\mathrm{AU}$ is more versatile in characterizing modulus changes than is the resonant frequency method [15] since the resonant frequency methods require nodal excitation and generation and are thus not applicable for scanning. 
Stress-Strain Curves for $\mathrm{SiC} / \mathrm{SiC}$ 0/90 Specimen

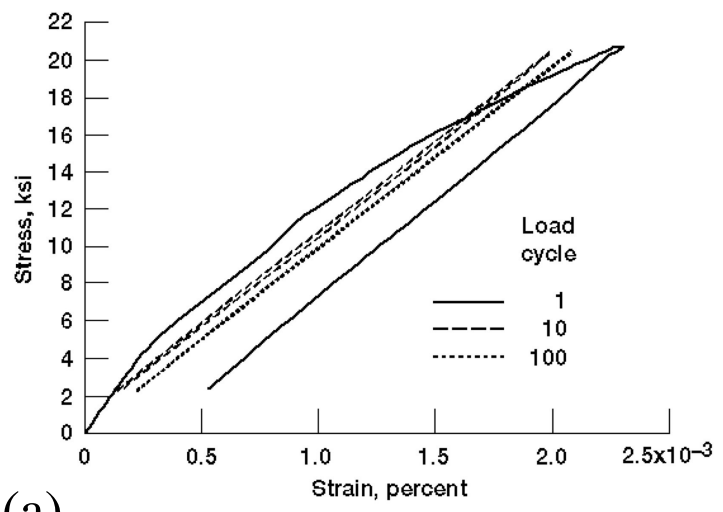

(a)

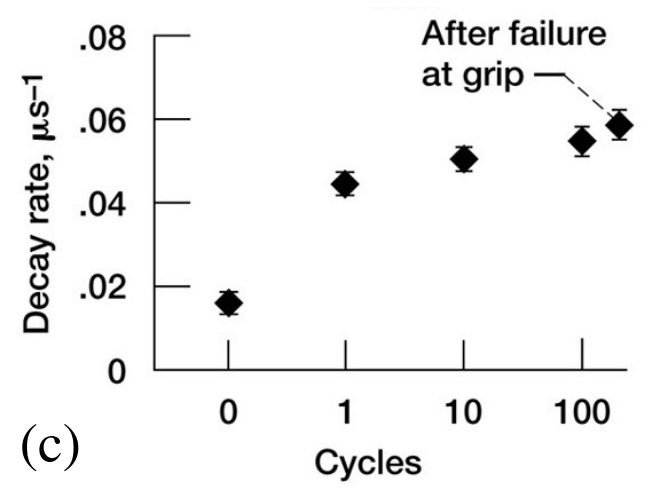

Before 1 Fatigue Cycle

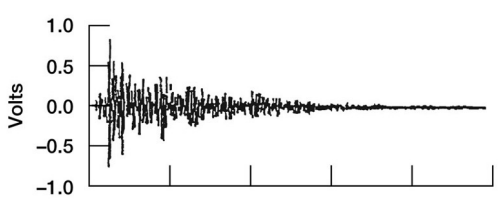

After 1 Fatigue Cycle

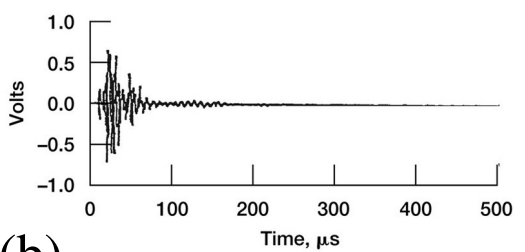

(b) 
exponential. Computational parameters such as centroid mean time and frequency distribution skewness that do not rely on model exponential decay behavior can be useful given non-model exponential waveform behavior. Thirdly, some AU signal processing has traditionally required iterative operator-dependent input regarding the portion and length of AU waveform to analyze and how to time segment the waveform for the calculation of $\beta$ (f) [7]. These decisions must be automated for scanning since it is obviously not practical (nor valid) to make such decisions on a point-by-point basis.

\section{DESCRIPTION OF PROTOTYPE AU SCANNER}

The AU scan system has been under development in-house at NASA Glenn Research Center for the past year. It is planned to have both automated scan and interactive point measurement capabilities within one system. It was desired to have all functions automated with software interfaces replacing hardware instruments where possible. The scan capability is close to completion with regards to the basic operations of motion control, load control, data acquisition, on-line pre- and post-signal processing, and waveform data/image recording and saving. The system has the following specifications:

- $\quad \geq 1 \mathrm{GHz}$ Pentium 4 PC-based system with Windows 2000 operating system.

- Software for driving the data and control system developed using LabVIEW 6.1 software language. Employment of state machine software coding architecture and nested tab control front panel architecture [16].

- Contact measurements made using immersion ultrasonic sending and receiving transducers having $2 \mathrm{~mm}$ × $2 \mathrm{~mm}$ RTV sealant pads affixed to the transducer face.

- 14-bit, 5 - $100 \mathrm{MHz}$ A/D converter PCI board residing within PC for ultrasonic data acquisition.

- $35 \mathrm{MHz}$ Ultrasonic pulser-receiver board residing within PC (under development for compatibility with Windows 2000 so external pulser-receiver presently is being used).

- $\quad$ PC interfaced to external X-Y motion control hardware (via serial port). For Z motion, employment of a pneumatically controlled actuator (with load cell) activated via computer parallel port. X-Y stages with $12.5 \mu \mathrm{m}$ resolution.

- Timer/counter PCI board residing within PC to measure motion stage positions.

- 8-bit $200 \mathrm{kHz}$ A/D converter PCI board residing within PC for load measurement.

Basic capabilities include:

- Tab control software interface with major functions of the scanner such as setup, data acquisition, and data display on each tab; and subfunctions of the major functions on nested tabs within the main tab (figure 4).

- Real-time time domain waveform and frequency domain power spectral density oscilloscope displays on major tabs.

- Digital signal pre- and post-processing including filtering, windowing, timesegmenting, and running waveform averaging.

- On-line (during scan) image calculation. 
- Post-scan image analysis and processing.

- Modes that allow waveform acquisition simulation and scan simulation to allow non-instrument-based programming to proceed off-line.

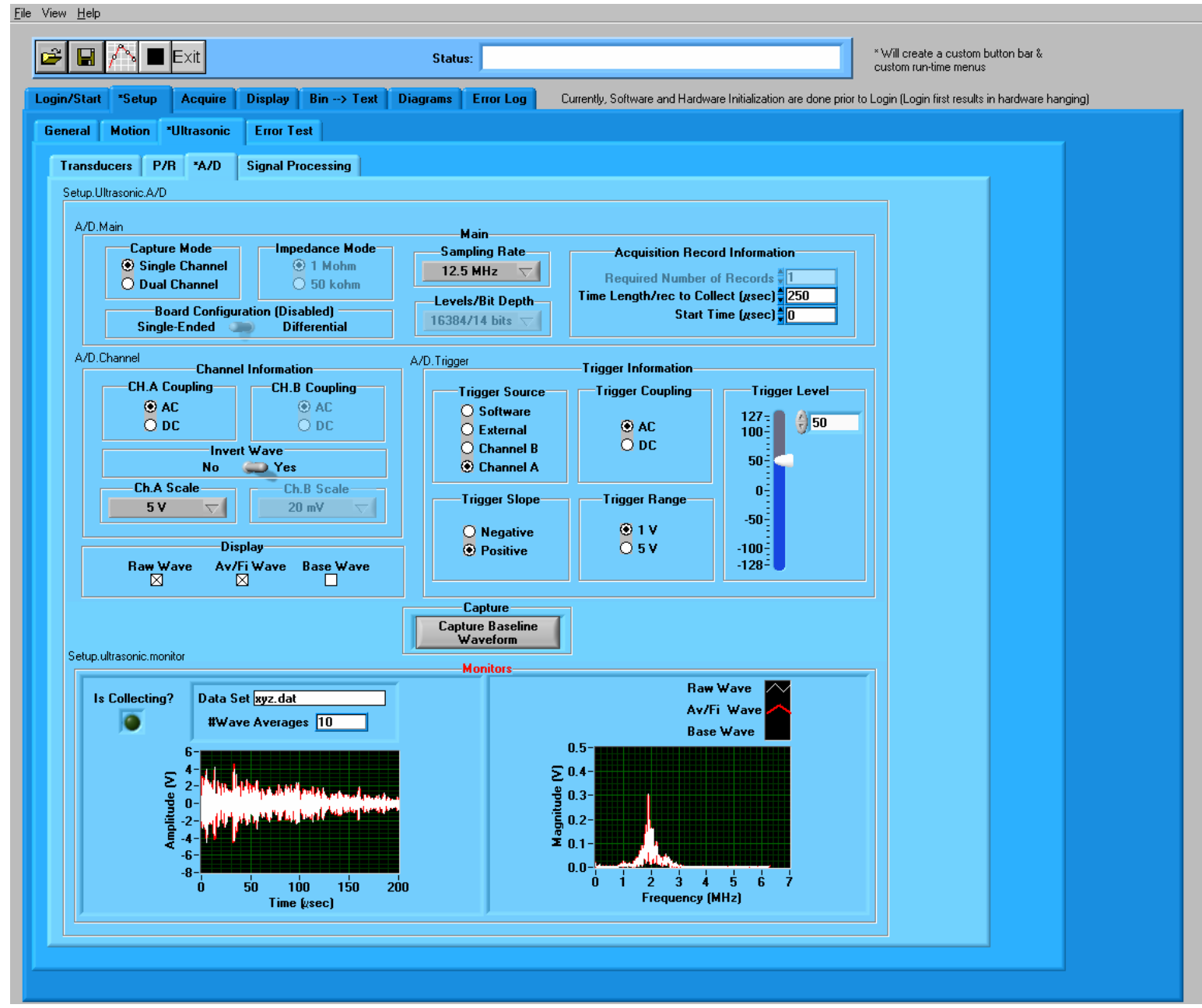

FIGURE 4. Nested Tab Control Software Interface. Tab selected is A/D tab nested within Ultrasonic tab which is nested within Setup tab. Live time-based and frequency domain displays are located on major tabs.

A different approach to a robotic AU scan system has been implemented by Workman, et al. [17].

\section{PRELIMINARY RESULTS}

Figure 5 shows a thermographic image of a portion of a $2 \mathrm{~mm}$ thick $\mathrm{SiC} / \mathrm{SiC}$ composite panel. A pattern of material density variation as shown by the grid of dark spots is shown and due to the manufacturing process. An AU scan of the same area was performed using a 126 by 51 grid of measurements with $1 \mathrm{~mm}$ scan increment. $2.25 \mathrm{MHz}$ center frequency transducers were used for both sending and receiving. Center-to-center distance between 
sending and receiving transducers was $25 \mathrm{~mm}$ (and thus this was the length of material interrogated at each scan location). With ultrasonic velocity estimated at $\sim 0.8 \mathrm{~cm} / \mu \mathrm{sec}, \lambda / \mathrm{h}$ $\simeq 1.8<2$ which indicates that the experimental conditions yielded the regime where higher-order plate wave modes should be generated. Figure 6 shows the AU centroid mean time image calculated from the raw scan data. A pattern of variation indicated by dark areas (short centroid mean times) is indicated that correlates with that seen in the thermographic image (figure 5). Although the regular pattern of density variation is more clearly indicated in the thermographic image, the AU centroid mean time image shows the capability of AU for indicating global microstructural differences.

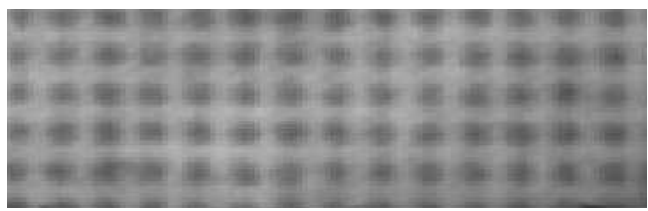

$2 \mathrm{~cm}$

FIGURE 5. Thermographic Image of approximately the same portion of panel shown in figure 5.

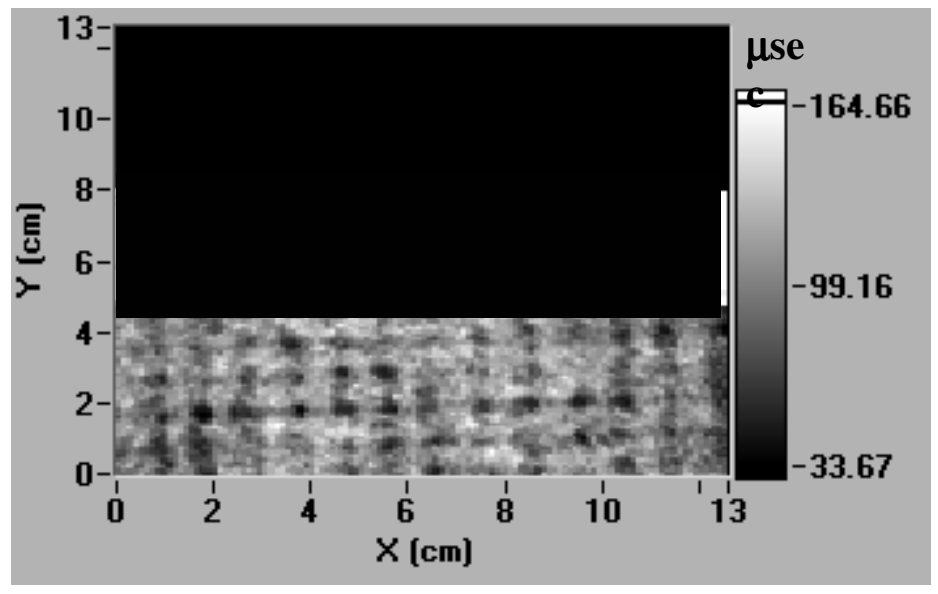

FIGURE 6. Centroid mean time $(\mu \mathrm{sec})$ image calculated from the $125 \mathrm{~mm} \times 50 \mathrm{~mm}$ AU scan of a $\mathrm{SiC} / \mathrm{SiC}$ composite panel. Scan Increment was $1 \mathrm{~mm}$.

\section{CONCLUSIONS AND FUTURE WORK}

This article addressed the acousto-ultrasonic (AU) inspection method and the prototype design of an AU scan system. Preliminary results obtained on a ceramic matrix composite sample are shown and reveal density variation similar to that seen in the thermographic image. Work to be completed includes further automation of signal processing parameters that have traditionally been operator-dependent in AU, the testing of time-frequency based signal processing methods to extract further information from the AU waveforms, implementation of the interactive point measurement mode, verification of the repeatability/precision of scans, basic studies involving testing composites of wellcharacterized microstructures to gauge sensitivity and resolution of the scan method and 
the various calculated parameters, and application to characterization of damage state in composites during research studies of mechanical and environmental property durability.

\section{REFERENCES}

1. Vary, A. and Bowles, K.J., "Ultrasonic Evaluation of the Strength of Unidirectional Graphite Polyimide Composites," Proceedings of the Eleventh Symposium on Nondestructive Evaluation, ASNT, San Antonio, TX, (1977) pp. 242-258.

2. Vary, A. and Bowles, K.J., "Use of an Ultrasonic-Acoustic Technique for Nondestructive Evaluation of Fiber Composite Strength," Reinforced PlasticsContact 78, Proceedings of the $33^{\text {rd }}$ Annual Conference, Society of the Plastics Industry, New York, 1978, Section 24-A, pp. 1-5.

3. Vary, A. and Lark, R.F., "Correlation of Fiber Composite Tensile Strength with the Ultrasonic Stress Wave Factor,” J. Test. Eval., Vol. 7, No. 4, pp. 185-191 (1979).

4. Kautz, H.E., Bowman, C., and Baaklini, G.Y., "Comparison of Contact and NonContact Acousto-Ultrasonic NDE on Fatigue Cycled SCS-6/Ti 6-4 Metal Matrix Composite Tensile Specimens," submitted to Res. Nondestructive Eval. (2002).

5. Pierce, S.G., Culshaw, B., Philp, W.R., Lecuyer, F., Farlow, R., "Broadband Lamb wave measurements in aluminum and carbon/glass fibre reinforced composite materials using non-contacting laser generation and detection," Ultrasonics, Vol. 35, pp. 105-114 (1997).

6. Kiernan, M.T. and Duke, J.C., "PC Analysis of an Acousto-Ultrasonic Signal," Materials Evaluation, Vol. 46, Sept., pp. 1344-1352 (1988).

7. Kautz, H.E., "Acousto-Ultrasonics to Assess Material and Structural Properties," NASA/CR-2002-211881 (2002).

8. Kautz, H.E., "New Acousto-Ultrasonic Techniques Applied to Aerospace Materials," Conference on Non-Destructive Testing and Evaluation for Manufacturing and Construction," University of Illinois, Urbana, Illinois, NASA TM-101299 (1988).

9. Tang, B. and Henneke II, E.G., "Long Wavelength Approximation for Lamb Wave Characterization of Composite Laminates," Res. Nondestr. Eval., Vol. 1, No. 1, pp. 51-64 (1989).

10. Lott, L.A., Kunerth, D.C., and Characklis, G.W., "Acousto-Ultrasonic NDE of Ceramic Matrix Composites," International Gas Turbine and Aeroengine Congress and Exposition. Orlando, Florida, June 3-6, 1991.

11. Kautz, H.E., "Acousto-Ultrasonic Decay in Metal Matrix Composite Panels," NASA TM-106972 (1995).

12. Gyekenyesi, A.L., Kautz, H.E., and Cao, W., "Damage Assessment of Creep Tested and Thermally Aged Udimet 520 Using Acousto-Ultrasonics," NASA/TM-2001210988, (2001).

13. Morscher, G.N. and Gyekenyesi, A.L., "The velocity and attenuation of acoustic emission waves in $\mathrm{SiC} / \mathrm{SiC}$ composites loaded in tension," Composites Science and Technology, Vol. 62, pp. 1171-1180 (2002). 
14. Gyekenyesi, A.L., Harmon, L.M., and Kautz, H.E., "The Effect of Experimental Conditions on Acousto-Ultrasonic Reproducibility," Proceedings of SPIE 2002, NDE and Health Monitoring of Aerospace Materials and Civil Infrastructures, San Diego, California, March, 2002.

15. ASTM Standard: C1259-96 "Standard Test Method for Dynamic Young's Modulus, Shear Modulus, and Poisson's Ratio for Advanced Ceramics by Impulse Excitation of Vibration."

16. Roth, D.J., LabVIEW Technical Resource, Vol. 8 No. 3, pp. 18-23 (2000).

17. Workman, G.L. and Walker, J., "Update On the Development of a Robotic AcoustoUltrasonic System," Proceedings of the $14^{\text {th }}$ World Conference on Non Destructive Testing (14 ${ }^{\text {th }}$ WCNDT), New Delhi, India, pp. 2067-2070, 1997. 


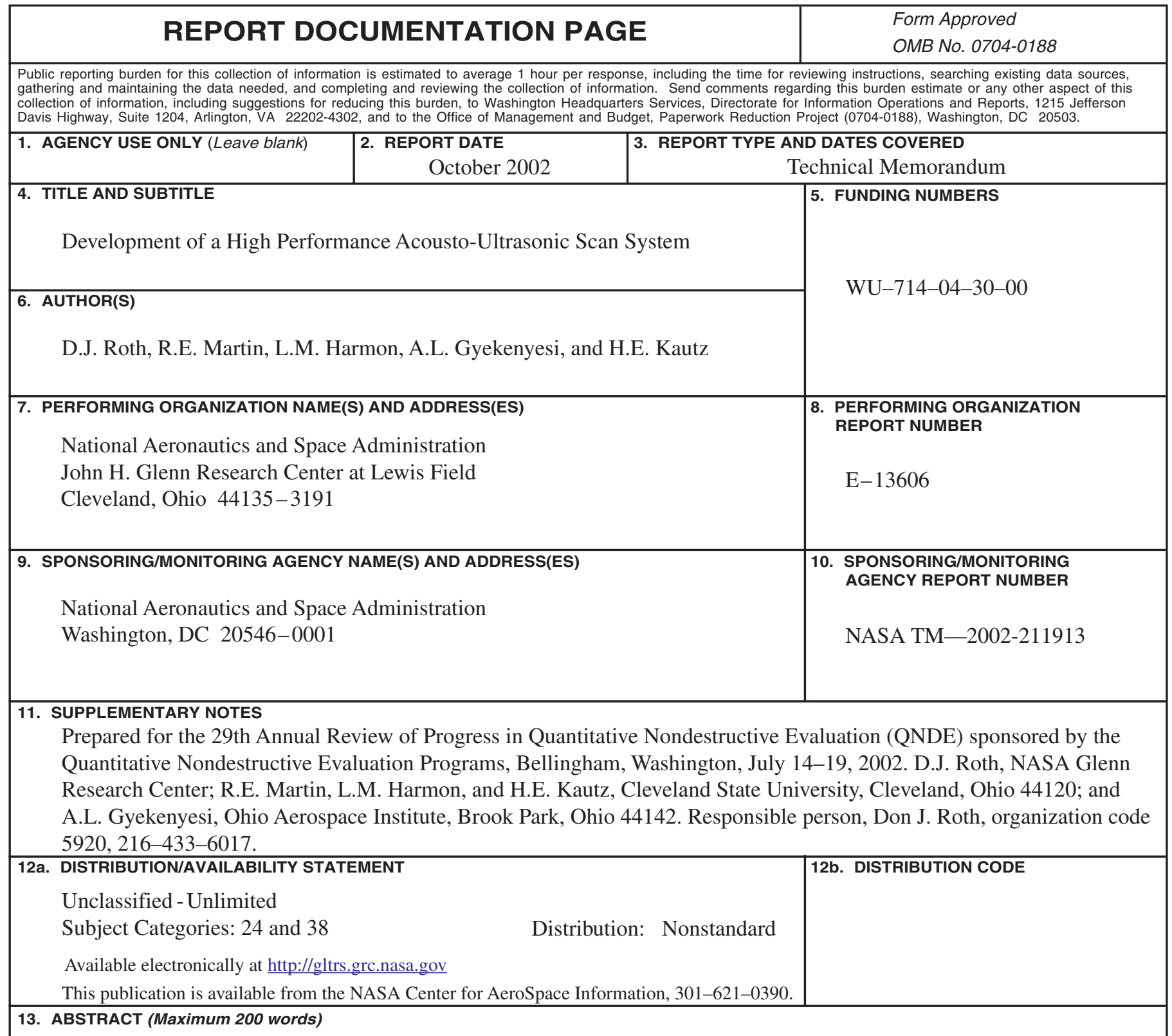

Acousto-ultrasonic (AU) interrogation is a single-sided nondestructive evaluation technique employing separated sending and receiving transducers. It is used for assessing the microstructural condition/distributed damage state of the material between the transducers. AU is complementary to more traditional NDE methods such as ultrasonic c-scan, $\mathrm{x}$-ray radiography, and themographic inspection that tend to be used primarily for discrete flaw detection. Through its history, AU has been used to inspect polymer matrix composite, metal matrix composite, ceramic matrix composite, and even monolithic metallic materials. The development of a high-performance automated AU scan system for characterizing within-sample microstructural and property homogeneity is currently in a prototype stage at NASA. In this paper, a review of essential AU technology is given. Additionally, the basic hardware and software configuration, and preliminary results with the system, are described.

\begin{tabular}{|c|c|c|c|}
\hline & 15. NUMBER OF PAGES \\
\hline \multicolumn{3}{|c|}{$\begin{array}{l}\text { 14. SUBJECT TERMS } \\
\text { Acousto-ultrasonics; Scanning; Composites }\end{array}$} & $\begin{array}{l}15 \\
\text { 16. PRICE CODE }\end{array}$ \\
\hline $\begin{array}{l}\text { 17. SECURITY CLASSIFICATION } \\
\text { OF REPORT }\end{array}$ & $\begin{array}{l}\text { 18. SECURITY CLASSIFICATION } \\
\text { OF THIS PAGE }\end{array}$ & $\begin{array}{l}\text { 19. SECURITY CLASSIFICATION } \\
\text { OF ABSTRACT }\end{array}$ & 20. LIMITATION OF ABSTRACT \\
\hline Unclassified & Unclassified & Unclassified & \\
\hline
\end{tabular}

